\title{
Reflexões sobre os benefícios da integração dos programas Ruas de Lazer e Ciclofaixas de Lazer em São Paulo
}

\author{
Reflections about the benefits of integrating the Ruas de Lazer and \\ Ciclofaixas de Lazer programs in Sao Paulo
}

Thiago Hérick de Sá1, Leandro Martin Totaro Garcia', Douglas Roque Andrade²

\begin{abstract}
Resumo
Assegurar o direito constitucional ao lazer e à atividade física é um desafio em grandes cidades como São Paulo. Para enfrentá-lo, a cidade conta com dois programas que ampliam o uso e a democratização dos espaços públicos de lazer por meio do fechamento total ou parcial de ruas: as Ruas de Lazer e as Ciclofaixas de Lazer. Este trabalho apresenta ambos os programas e discute possíveis ganhos sinérgicos da aproximação dessas duas iniciativas para a melhoria da qualidade de vida da população paulistana. Também, apresenta-se a ideia de uma 'Teia de Lazer e Atividade Física' na cidade, que englobe ações e equipamentos públicos e privados, tendo como ponto de partida a integração das Ruas de Lazer e Ciclofaixas de Lazer.
\end{abstract}

\section{Palavras-chave}

Política social; Formulação de políticas; Atividade motora; Atividades de lazer; Ambiente social

\begin{abstract}
Assuring the constitutional right to leisure and physical activity is a challenge in large cities as Sao Paulo. To face it, the city has two programs that expand the use and democratization of public spaces for leisure through full or partial closure of streets: the Ruas de Lazer (Open Streets) and the Ciclofaixas de Lazer (Leisure Cycle Tracks). This paper presents both programs and discusses possible synergistic gains of approaching these two initiatives to improve the quality of life of Sao Paulo population. In addition, it presents the idea of a 'Leisure and Physical Activity Network' in the city, encompassing public and private actions and equipment, having as starting point the integration of the Ruas de Lazer and Ciclofaixas de Lazer.
\end{abstract}

\section{Keywords}

Public Policy; Policy Making; Motor Activity; Leisure Activities; Social Environment

nesse sentido é a ampliação do acesso e democratização dos espaços públicos de lazer, como os programas de fechamento total ou parcial de ruas, extensamente utilizados em diversas cidades nas Américas ${ }^{4} \mathrm{e}$ com reconhecidos benefícios à saúde da população ${ }^{5,6}$. Esses programas facilitam o acesso ao lazer principalmente em regiões onde há carência de espaços para a prática, aproveitando-se do viário público. Muito embora esses programas compartilhem um princípio em comum - abrir as ruas da cidade para as pessoas, fechando-as para o trânsito - há ampla variabilidade em termos de organização, execução e governança, o que influencia diretamente o tipo de participante, a forma de participação e o custo-efetividade do programa ${ }^{7}$. Além disso, há diferentes terminologias para esse tipo de programa por toda a América (Peru, Colômbia, Estados Unidos, Canadá, Guatemala, dentre 
outros), como Ciclovias Recreativas, Open Streets, Ruas de Lazer, Ciclofaixas de Lazer e Áreas de Lazer.

A cidade de São Paulo apresenta dois programas de fechamento de ruas, as Ruas de Lazer e as Ciclofaixas de Lazer, bastante distintos em sua história e constituição, e, consequentemente, diferentes em suas potencialidades e limitações. Além de apresentar brevemente essas duas iniciativas, nosso comentário tem por objetivo discutir os possíveis ganhos sinérgicos da aproximação desses dois programas na ampliação do acesso e democratização do espaço público como estratégia para a melhoria da qualidade de vida da população paulistana.

\section{Ruas de Lazer}

Na cidade de São Paulo, a rua figura como espaço de prática de atividade física institucionalmente reconhecido pelo menos desde 1924, ano da primeira maratona de São Silvestre. No entanto, programas como a Rua de Lazer tiveram sua origem no Brasil em 1957, a partir do movimento "Ruas de Recreio", coordenado pelo professor Alfredo Colombo na cidade de Rio de Janeiro ${ }^{8}$.

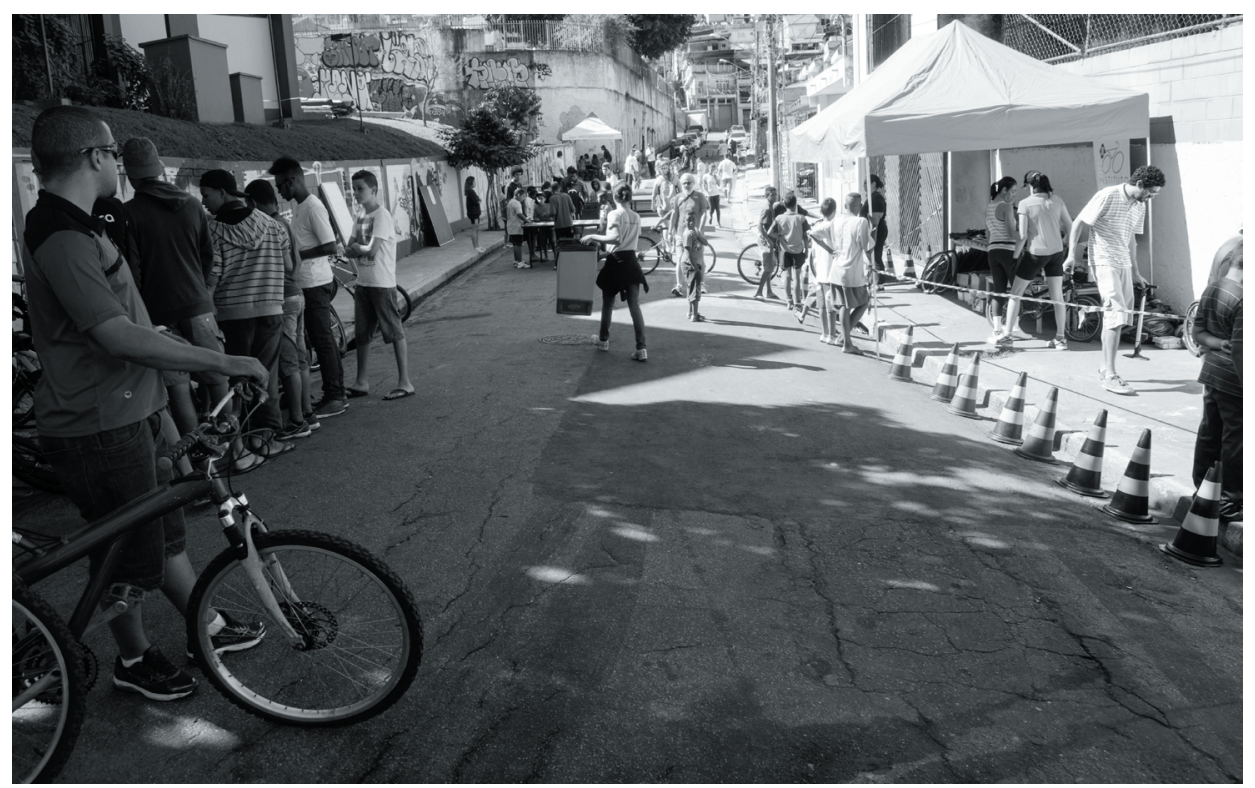

FIGURA 1 - Rua de Lazer na cidade de São Paulo. Foto: Antonio Miotto.

Na cidade de São Paulo, o programa Ruas de Lazer está em funcionamento desde $1976^{9}$, sendo um interessante exemplo de política pública inspirada no poder transformador dos cidadãos e com grande potencial de sustentabilidade. Após doze anos de insistência, Dona Dirce, moradora da zona leste de São Paulo, conseguiu o direito de interditar a rua de sua casa aos domingos e feriados para que as crianças pudessem brincar, criando, assim, a primeira Rua de Lazer da cidade ${ }^{10}$. Essa história exemplifica a forte participação popular e empoderamento individual e comunitário no programa, desde a criação da rua até a sua organização. Existem aproximadamente mil ruas de lazer cadastradas, espalhadas por todo o município, sobretudo nas regiões mais pobres, todas sob a responsabilidade da Secretaria Municipal de Esportes, Lazer e Recreação (SEME) em parceria com a Companhia de Engenharia de Tráfego $(\mathrm{CET})^{9}$.

As Ruas de Lazer consistem no fechamento total de um trecho da rua (geralmente, uma quadra) aos domingos e feriados, das $9 \mathrm{~h}$ às $17 \mathrm{~h}$, para a prática de qualquer atividade de lazer (Figura 1). Cada rua nasce da iniciativa dos moradores, 
que devem submeter ao poder público, dentre outras exigências, um abaixo-assinado com a aprovação de pelo menos dois terços dos moradores do trecho a ser fechado, e um conselho gestor, responsável pela coordenação do evento e guarda dos equipamentos cedidos pela prefeitura (cavaletes para bloquear a via e kits esportivos $)^{11}$. Esse modelo de cogestão torna o custo do programa relativamente baixo, assim como sua regularidade e sustentabilidade fortemente dependentes do grau de autonomia, mobilização e organização local. Seu ininterrupto funcionamento por décadas, sem intensas ações de promoção do programa na maior parte do tempo, é um ponto positivo dessa estratégia de parceria entre o poder público e a comunidade. Por outro lado, sabe-se que uma quantidade importante das Ruas de Lazer cadastradas não está em funcionamento ou funciona de forma infrequente, em parte por não haver reposição ou manutenção dos equipamentos inicialmente ofertados pela prefeitura, por decaimento do interesse e da participação dos moradores, ou por pressão de moradores da própria rua ou de ruas vizinhas para que o trecho não seja fechado ao trânsito. Não há estimativas recentes sobre a quantidade de participantes em cada evento e no conjunto das Ruas de Lazer em cada final de semana. Além disso, esse programa parece ser gerido por uma quantidade insuficiente de profissionais na SEME, o que além de fragilizar sua gestão e sustentabilidade, também torna difícil a obtenção de informações atualizadas e acuradas sobre o seu funcionamento.

A oferta de um espaço público sem função pré-definida e passível de múltiplos usos é uma das forças das Ruas de Lazer, pois oportuniza a manifestação das preferências locais de cultura e lazer, além de possibilitar o uso da rua simultaneamente por diferentes subgrupos de idade. Por outro lado, a preocupação do poder público em não comprometer o tráfego de veículos com o fechamento das ruas acaba por isolar cada evento, dificultando a constituição de uma rede integrada de Ruas de Lazer e de seu fortalecimento. Uma extensa rede de Ruas de Lazer, como podemos observar em cidades como Bogotá $(121 \mathrm{~km})^{12}$, permitiria a integração entre diferentes comunidades da cidade, assim como o acesso a outros programas e equipamentos públicos de lazer e cultura, como parques, clubes e teatros. Ademais, em alguns poucos lugares de São Paulo, existem Ruas de Lazer mais extensas, com o fechamento de várias quadras, embora esses fechamentos geralmente não nasçam do recolhimento de assinaturas da comunidade. Além disso, a maior Rua de Lazer contígua da cidade, no Elevado Presidente João Goulart ("Minhocão"), depende do resultado da intensa discussão na sociedade paulistana sobre o futuro desse viário.

\section{Ciclofaixas de Lazer}

Fruto de uma parceria entre o poder público e a iniciativa privada e em funcionamento desde 2009, o programa Ciclofaixas de Lazer consiste no fechamento parcial da rua (geralmente, uma faixa em cada direção) aos domingos e feriados, das 7 h às $16 \mathrm{~h}$, para o uso da bicicleta (Figura 2). O programa passou por sucessivas ampliações do percurso, que contava, em janeiro de 2017, com 120,8 km (contabilizando o percurso de ida e volta $)^{13}$. Boa parte do percurso está interconectada e também interliga diversos parques, estruturas cicloviárias permanentes e equipamentos públicos da cidade, como, por exemplo, as atrações históricas e culturais do centro da cidade. Estima-se uma participação de 120 mil pessoas por evento ${ }^{14}$. As Ciclofaixas de Lazer também estão sob a responsabilidade da SEME e contam com o apoio da CET e da Federação Paulista de Ciclismo, além de patrocínio privado. Inspiradas no modelo paulistano, outras cidades brasileiras, como Recife, Fortaleza e Florianópolis, também criaram programas similares. Em comum a 
todas essas cidades, está a implantação do percurso inicialmente nas regiões mais centrais e sua posterior expansão para outras áreas da cidade.

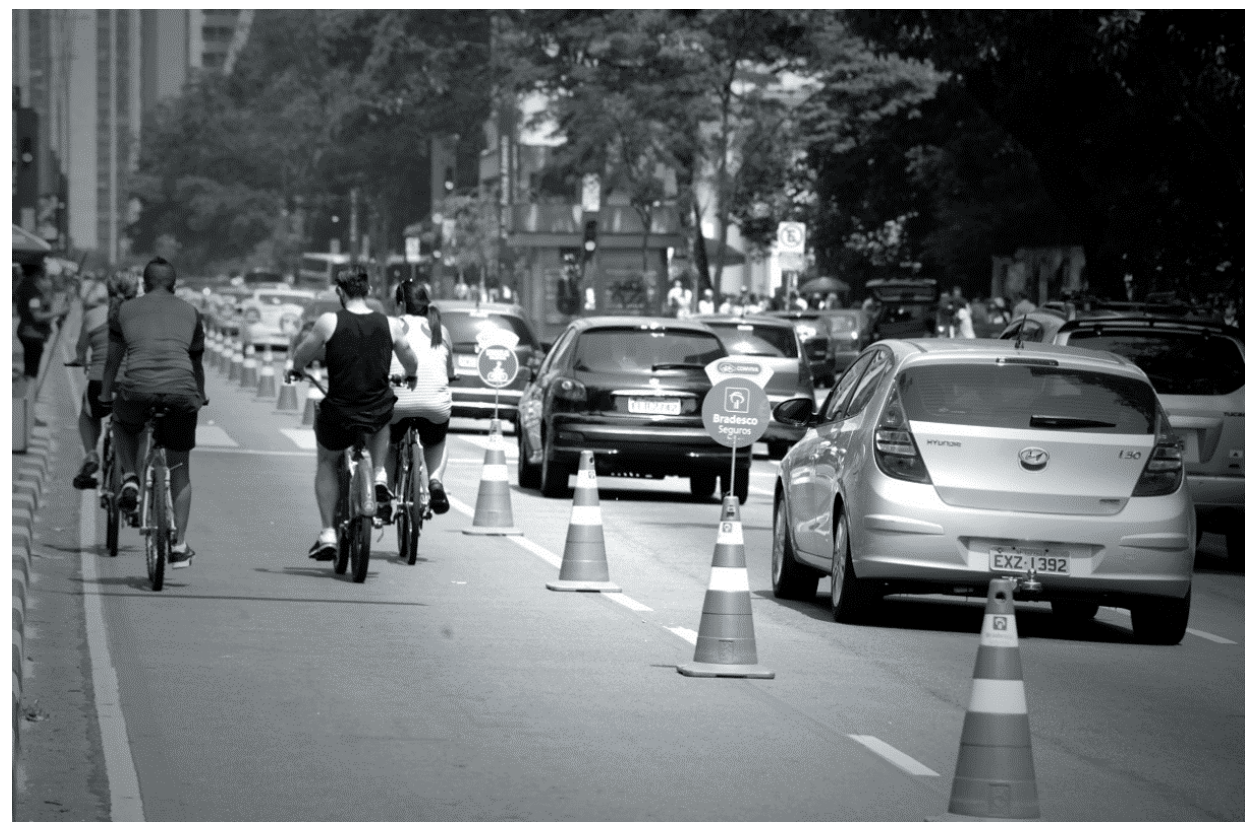

FIGURA 2 - Ciclofaixa de Lazer na cidade de São Paulo. Foto: Oswaldo Corneti / Fotos Públicas.

Ao contrário das Ruas de Lazer, a decisão sobre o percurso das Ciclofaixas de Lazer é uma atribuição da SEME e de seus apoiadores, com participação limitada da população. O fechamento parcial da via é feito por estruturas móveis, como cones de trânsito, além de existir um controlador de fluxo em cada cruzamento da via onde está a ciclofaixa com as demais ruas. Além disso, ao longo do percurso, há equipes de emergência, de segurança e de manutenção de bicicletas.

Esse modelo de organização é uma interessante solução para a ampliação de espaços públicos de lazer em regiões com alto volume de tráfego de veículos. Por outro lado, essas características fazem das ciclofaixas um espaço de lazer regido pela mesma lógica do trânsito, com fluxo contínuo e orientado, privilégio a um modo de transporte / lazer (bicicleta) e menor diversidade de participação e interação social. Ademais, é preciso considerar os potenciais riscos para a sustentabilidade das Ciclofaixas de Lazer, dado seu maior grau de complexidade e participação de outros atores além do setor público, tanto no financiamento quanto na organização.

\section{Ganhos sinérgicos da aproximação entre os programas Ruas de Lazer e Ciclofaixas de Lazer}

Como vimos, muito embora compartilhem a mesma função finalística de devolver à rua o sentido de espaço público para o exercício da cidadania ${ }^{15}$ e tenham diversas características em comum, os programas Ruas de Lazer e Ciclofaixas de Lazer apresentam qualidades distintas e, por vezes, complementares. Há, portanto, diversas oportunidades de aproximação, que vão desde a troca de experiências até a integração espacial e organizacional, com potenciais benefícios para a população paulistana.

A integração espacial e a apropriação do território talvez sejam as oportunidades mais imediatas de aproximação, com a interligação das Ruas de Lazer por meio das ciclofaixas e de sua expertise em minimizar os impactos dos fechamentos ao trânsito de veículos. A construção dessa 'Teia de Lazer e Atividade Física' (Figuras 3 e 4), fomentada e organizada pelo poder público, e estruturada em torno da participação 
popular, possibilitaria ampliar o contato entre diferentes núcleos sociais construídos em torno de cada Rua de Lazer e desses com diversos equipamentos públicos da cidade, a partir da maior circulação de pessoas. Também permitiria a ampliação de atividades culturais, esportivas e de utilidade pública - como acontece em outras cidades do mundo, como Bogotá - contribuindo, assim, para redução da segregação espacial e social presente na cidade. Mais ainda, poder-se-ia fomentar a criação de novas Ruas de Lazer nas proximidades do percurso das ciclofaixas, que, juntamente com as ruas já existentes, funcionariam como pequenos bolsões de lazer ("pocket parks" ${ }^{16}$, nos quais atividades culturais e esportivas são mais facilmente desenvolvidas. Essa lógica de ordenamento espacial já ocorre parcialmente no atual modelo das Ciclofaixas de Lazer, em que parques e praças funcionam como espaço de lazer de fluxo difuso e as ciclofaixas de fluxo orientado. O conceito de bolsão de lazer é particularmente interessante em regiões com menor densidade de praças e parques, justamente onde hoje está a maior parte das Ruas de Lazer, contribuindo com o sentimento de pertencimento, territorialidade e o empoderamento comunitário.

Interessante observar como esses potenciais ganhos sinérgicos contribuiriam para a promoção da saúde, bem como com o cumprimento de diversas metas do programa municipal de governo da gestão anterior ${ }^{17}$ - muitas das quais incompletas até o final da gestão - como, por exemplo, "Promover a prática de atividades esportivas, recreativas e de lazer por 24 horas aos finais de semanas nas 32 subprefeituras" (Meta 47; 66\% incompleta). A integração das Ciclofaixas de Lazer e das Ruas de Lazer também poderia estar contemplada nos programas de requalificação do espaço público e melhoria do centro e dos bairros (Meta 72; 49\% incompleta) e colaborar com os objetivos de "ampliar o acesso da população a cultura, por meio de equipamentos e ações, a partir da descentralização do território" (Metas 27, 29 e 30; $87 \%, 53 \%$ e $28 \%$ incompletas) e de "prevenção da violência, do racismo e da exclusão da juventude negra e de periferia” (Meta 43; 70\% incompleta).

Do ponto de vista organizacional e de governança, vale destacar que ambos os programas estão sob a responsabilidade do mesmo órgão municipal (SEME) e com apoiadores em comum, como a CET, e poderiam aproximar-se dos serviços e políticas do setor da saúde em função de vários princípios de promoção da saúde envolvidos nos dois programas. A integração organizacional poderia favorecer a troca de experiências, como o fortalecimento da participação popular (Ruas de Lazer) ou os desafios logísticos de um programa mais complexo (Ciclofaixas de Lazer). Também poderia, por meio do compartilhamento, otimizar recursos financeiros, humanos e logísticos, além de possibilitar o planejamento de iniciativas conjuntas, como a construção de um calendário comum de ações turísticas, culturais e esportivas, tornando-os mais sustentáveis. Conta a favor dessa iniciativa a sobreposição de datas e horários de funcionamento de ambos os programas. Para tanto, seria importante explicitar detalhes sobre o orçamento destinado a cada programa: no plano plurianual da prefeitura de São Paulo (2014 - 2017), está definido o valor de 80 milhões de reais para executar a implantação de vias cicláveis (ciclovias, ciclofaixas e ciclorrotas), totalizando $242,52 \mathrm{Km}$, sem a especificação sobre a inclusão ou não das Ciclofaixas de Lazer nessa rubrica - ainda que estruturas cicloviárias permanentes também possam contribuir para a efetivação da teia de lazer e atividade física. No mesmo documento, não há nenhuma menção ao programa Ruas de Lazer.

A avaliação do processo e do impacto dos dois programas à saúde e à qualidade de vida da população é outro ponto crucial dessa aproximação, na medida em que é fundamental conhecer quais são as estratégias mais efetivas para ampliar e democratizar o acesso da população à cidade e aos espaços públicos de lazer. Faz-se 


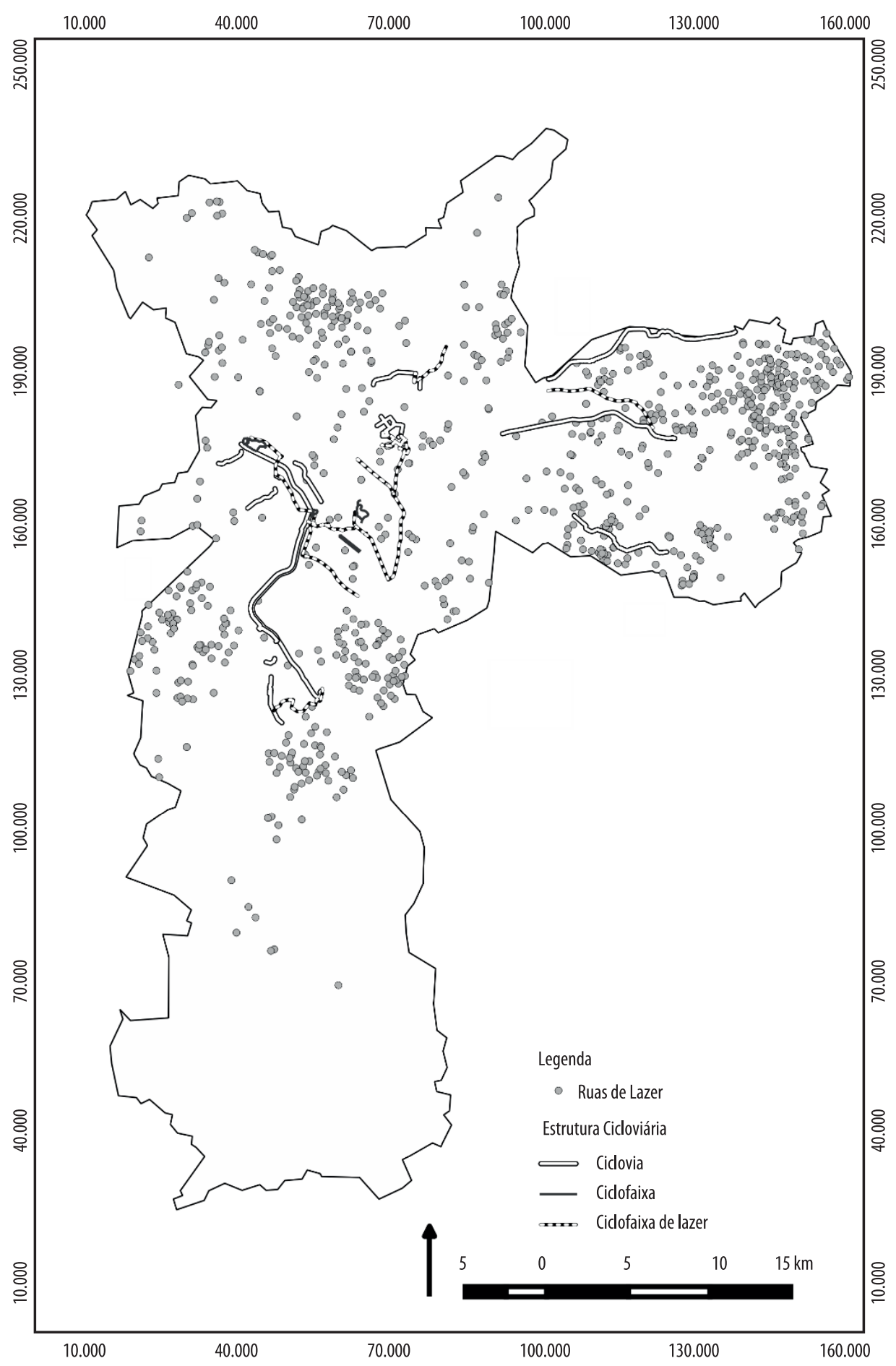

FIGURA 3 - Distribuição das Ruas de Lazer, das Ciclofaixas de Lazer e das estruturas cicloviárias permanentes na cidade de São Paulo. São Paulo, 2016.

necessária a ampliação do conhecimento sobre esses programas, mesmo em características básicas, como o perfil dos usuários e a quantidade de participantes em cada evento. Essas ações poderiam contar com o envolvimento ativo de universidades e institutos de pesquisa, ainda muito distantes.

A avaliação das Ruas de Lazer e Ciclofaixas de Lazer apresenta desafios metodológicos comuns, por serem programas multissetoriais (esporte e lazer, transporte, saúde, cultura, participação social, educação), com um relativo grau de complexidade de gestão e execução, e por se traduzirem em experimentos naturais de 


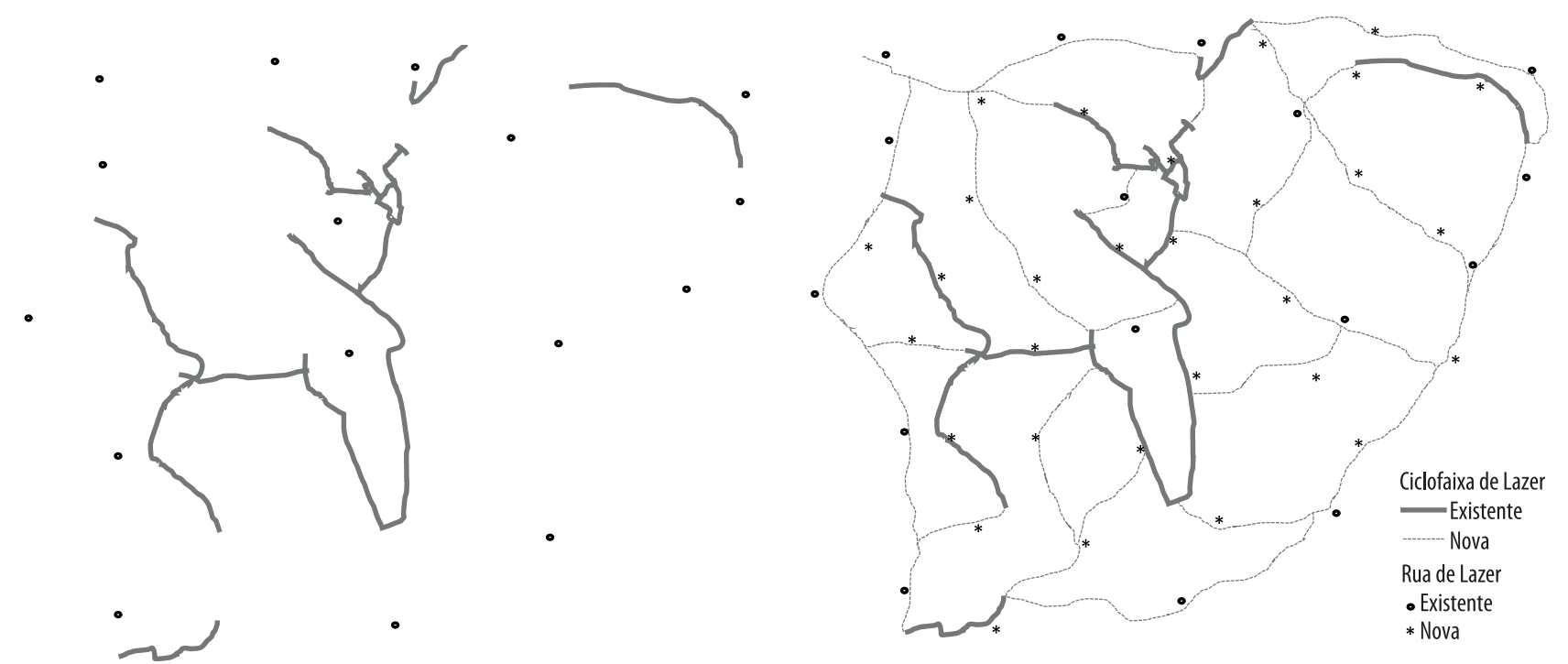

FIGURA 4 - Ilustração do conceito de Teia de Lazer e Atividade Física. Figura 4.a: representação atual das Ruas de Lazer e Ciclofaixas de Lazer. Figura 4.b: possível configuração de uma teia, conectando espacialmente os dois programas. São Paulo, 2016.

base comunitária de larga escala, com um conjunto de variáveis de processo e interações com a dinâmica da cidade. Esse tipo de programa tem tido baixa rejeição, ganhos à saúde da população e boa relação custo-benefício, inclusive no contexto das metrópoles sul-americanas ${ }^{18}$. Para citar dois exemplos de avaliação em outros países, cada dólar investido em programas similares ofereceu um retorno de US\$ 2,3 em San Francisco (EUA) e US\$ 3,2 a 4,2 em Bogotá, considerando apenas os benefícios à saúde da população ${ }^{7}$. Seria importante avaliar esses programas em detalhe também no contexto das metrópoles brasileiras.

\section{Considerações Finais}

Devolver à rua o status de espaço público para o exercício da cidadania é condição indispensável para a melhoria da qualidade de vida e da saúde da população. São Paulo tem o privilégio de contar com dois grandes programas cujo propósito é justamente esse. A integração das Ruas de Lazer e das Ciclofaixas de Lazer poderia servir como ponto de partida para o desenvolvimento de uma teia de lazer e atividade física que englobasse, de forma coordenada, ações e equipamentos públicos e privados, inclusive aqueles relacionados a outras esferas de poder - como o programa Escola da Família, organizado pelo governo estadual. A possível repercussão positiva dessa teia se daria não apenas no município, mas em toda a região metropolitana (39 municípios, 21 milhões de habitantes) e mesmo como exemplo outras capitais brasileiras, como vimos no caso da Ciclofaixa de Lazer.

Entretanto, para que esses ganhos se efetivem, parece-nos fundamental a articulação dos diferentes atores envolvidos nesse processo - gestores públicos, comunidade, apoiadores privados e academia - em torno do esforço coletivo de efetivação do direito à saúde, ao lazer, à atividade física e, em última instancia, à cidade como um todo.

\section{Colaboração dos autores}

T. H. Sá concebeu a ideia original, apoiou na discussão sobre o tema, coleta de informações e redação do artigo. L. M. T. Garcia apoiou a discussão sobre o tema, coleta de informações, e redação do artigo. D. R. Andrade apoiou a discussão sobre o tema, coleta de informações e redação do artigo. Todos os autores aprovaram a versão submetida. 


\section{Agradecimentos}

T. H. Sá gostaria de agradecer à Fundação de Amparo à Pesquisa de São Paulo - Fapesp (Processo número: 2013/25624-7) e ao Conselho Nacional de Desenvolvimento Científico e Tecnológico (Processo número: 402648/2015-3). Os autores gostariam também de agradecer a Isis Ramos, por sua inestimável colaboração ao trabalho.

\section{Referências}

1. Instituto Brasileiro de Geografia e Estatística. Censo 2010: resultados do universo [online]; 2010. [citado 2016 out 3]. Disponível em: www.ibge.gov.br/home/estatistica/ populacao/censo2010/default_resultados_universo.shtm.

2. Brasil. Lei $n^{\circ}$ 8.080, de 19 de setembro de 1990: dispõe sobre as condições para a promoção, proteção e recuperação da saúde, a organização e o funcionamento dos serviços correspondentes e dá outras providências [online]; 1990. [citado 2016 out 3]. Disponível em: https://www.planalto.gov.br/ccivil_03/leis/18080.htm.

3. Brasil. Lei $\mathrm{n}^{\circ} 12.864$, de 24 de setembro de 2013: altera o caput do artigo $3^{\circ}$ da Lei no 8.080, de 19 de setembro de 1990, incluindo a atividade física como fator determinante e condicionante da saúde [online]; 2013. [citado 2016 out 3]. Disponível em: http://www. planalto.gov.br/ccivil_03/_ato2011-2014/2013/lei/112864.htm.

4. Ciclovías Recreativas de las Américas [online]. [citado 2016 out 3]. Disponível em: http:// cicloviasrecreativas.esy.es/red.

5. Sarmiento O, Torres A, Jacoby E, Pratt M, Schmid TL, Stierling G. The CiclovíaRecreativa: A mass-recreational program with public health potential. J Phys Act Health. 2010;7(Suppl 2):S163-80.

6. Torres A, Sarmiento OL, Stauber C, Zarama R. The Ciclovia and Cicloruta programs: promising interventions to promote physical activity and social capital in Bogota, Colombia. Am J Public Health. 2013;103(2):e23-30.

7. Montes F, Sarmiento OL, Zarama R, Pratt M, Wang G, Jacoby E, et al. Do health benefits outweigh the costs of mass recreational programs? An economic analysis of four Ciclovia programs. J Urban Health. 2012;89(1):153-70.

8. DaCosta L. Atlas do esporte no Brasil [online]; 2005. [citado 2016 out 3]. Disponível em: http://www.confef.org.br/arquivos/atlas/atlas.pdf.

9. Prefeitura de São Paulo. Secretaria Executiva de Comunicação. Cidade de São Paulo possui mais de mil ruas de lazer [online]; 2013. [citado 2016 out 3]. Disponível em: www. prefeitura.sp.gov.br/cidade/secretarias/comunicacao/noticias/?p=142916.

10. Veiga E. Ela só queria uma rua para os filhos brincarem [online]; 2012. [citado 2016 out 3]. Disponível em: http://sao-paulo.estadao.com.br/blogs/edison-veiga/ela-so-queriauma-rua-para-os-filhos-brincarem.

11. Prefeitura de São Paulo. Decreto n. ${ }^{\circ} 38.872$, de 21 de dezembro de 1999: regulamenta a Lei n. ${ }^{\circ} 12.264$, de 11 de dezembro de 1996, que dispõe sobre a implantação de áreas de lazer no perímetro urbano da capital, e dá outras providências [online]; 1999. [citado 2016 out 3]. Disponível em: http://www.leispaulistanas.com.br/ruas-de-lazer/decretono-38872-de-21-de-dezembro-de-1999.

12. Alcaldía Mayor de Bogotá. Instituto Distrital de Recreación y Deporte. La ciclovía bogotana y su historia [online]. [citado 2016 out 3]. Disponível em: www.idrd.gov.co/ sitio/idrd/?q=es/node/1606.

13. Companhia de Engenharia de Tráfego. Ciclofaixa operacional de lazer [online]. [citado 2016 out 3]. Disponível em: www.cetsp.com.br/consultas/bicicleta/ciclofaixaoperacional-de-lazer.aspx.

14. Movimento Conviva. Infográfico \#Ciclofaixa5anos [online]. [citado 2016 out 3]. Disponível em: http://movimentoconviva.com.br/infografico-ciclofaixa5anos.

15. Augé M. Non-places: introduction to an anthropology of supermodernity. Londres: Verso; 1995.

16. Cohen DA, Marsh T, Williamson S, Han B, Derose KP, Golinelli D, et al. The potential for pocket parks to increase physical activity. Am J Health Promot. 2014;28(3 Suppl):S19-26.

17. Prefeitura de São Paulo. Planeja Sampa. Programa de metas 2013-2016 [online]. [citado 2016 out 3]. Disponível em: http://planejasampa.prefeitura.sp.gov.br/metas.

18. Heath GW, Parra DC, Sarmiento OL, Andersen LB, Owen N, Goenka S, et al. Evidencebased intervention in physical activity: lessons from around the world. Lancet. 2012;380(9838):272-81.

Endereço para

correspondência

Thiago Hérick de Sá

thiagoherickdesa@gmail.com 